\title{
Self-consciousness of Higher Education Instructors as Determinant of Personal Growth
}

\author{
Elena Petanova \\ Saint Petersburg State University \\ Faculty of Psychology \\ 7/9 Universitetskaya nab.,St. Petersburg, Russia 199034 \\ E-mail: e.petanova@spbu.ru
}

\author{
Radostina Stoyanova \\ Department of Slavic Philology \\ Saint Petersburg State University \\ 7/9 Universitetskaya nab., St. Petersburg, Russia 199034 \\ Department of Foreign Languages \\ College of tourism, University of Economics - Varna \\ 77 Kniaz Boris Blvd., 9002 Varna, Bulgaria \\ E-mail: r.stoyanova@spbu.ru
}

\begin{abstract}
The present paper discusses the significance of the self-consciousness concept for professional and personal growth of the higher education instructor. Theoretical and practical relevance of investigating the self-consciousness of higher education instructors was noted, level of knowledge of this problem was analyzed. Purpose of research: examine the phenomenology of self-consciousness in higher education instructors in the traditional university environment in the situation of professional and personal growth. Target of research: components of the self-consciousness of the higher education instructor. The subject of this research is the comparative analysis of relationships between structural components of the self-consciousness of the instructors who took part in a "self-analysis" exercise versus the reference group. Personal growth criterion was changes in the content and level of the following self-consciousness factors: cognitive and emotional-behavioral characteristics and symptoms reflecting the professional and personal problems of the instructors. Respondents were instructors from different departments (philology, history, journalism, sociology) with seniority of at least five years. The paper presents the findings of the empirical research in the relationships between the selfconsciousness components and provides interpretation of the findings. The research material can be useful for higher education instructors, psychologists and teachers researching the self-consciousness of the subjects of educational environment. The data presented in the paper can be used for planning psychological support programs targeted at higher education instructors, personal growth exercises and training programs for instructors and students of education and psychology colleges.
\end{abstract}

Keywords-personal growth; higher education instructor; self-consciousness; self-analysis; self-conception; selfunderstanding; life-purpose guides; behavioral styles; professional "burnout" symptoms; psychological defenses

\section{INTRODUCTION}

Dynamic reforms that changed the Russia's higher education system, along with the depth and controversial nature of such changes experienced at different levels and manifested in different aspects of practical teaching, call for particular requirements to on-going personal and professional growth of teaching staff at higher educational institutions.

In this connection, one can see that an undying interest to such an intriguing component of instructor's personality as his/her self-consciousness is justifiable; undoubtedly, the self-consciousness can be considered as one of the most significant determination factors for personal and professional development of the subjects of educational environment.

Hypothesis of research: "Personal growth" of the higher education instructor is dialectically associated with the functional components of his/her self-consciousness. The degree of manifestation of the relationships between the selfconsciousness components may vary in the course of professional and personal self-improvement.

Purpose of research is to look into patterns of relationships between different self-consciousness factors of the higher education instructor under the influence of selfanalysis. Subject of research is the comparative analysis of relationships between structural components of selfconsciousness of the instructors who took part in a "selfanalysis" exercise versus the reference group.. Relations were investigated between the following components: selfconception, life-purpose guides, conflict behavioral styles, defense mechanisms and symptoms reflecting professional "burnout".

Objective of research: study and compare the relationships between the self-consciousness components in two groups of instructors: (1) those who developed various aspects of the self-consciousness (in a situation of psychological and academic personal growth exercise); (2) reference group.

\section{DESIGN OF RESEARCH}

\section{A. The Research Process Comprised Three Phases}

At the first phase, maturity of the subject matter was evaluated. Self-consciousness components were determined that had significance in the hypothetical integral "self" 
construct of the higher education instructor, a general hypothesis of empirical research was formulated. Psychodiagnostic tools were selected. A psychodiagnostic survey of self-consciousness components was carried out, the degree of relationships between the components was established in the test and reference groups.

At the second phase, the test group attended the supplementary educational program "Higher education instructor" during one semester, psychological and pedagogical awareness and self-understanding of the test group were improved through a psychological exercise in "self-analysis of self-consciousness content", individual recommendations were prepared for self-adjustment of the personal attributes.

At the third phase (2-4 weeks after completing practical exercises), psychodiagnostic testing was repeated and a statistical analysis of the results was carried out. A comparative analysis of the relationships between the investigated self-consciousness components in the test and reference groups. Data from the initial and final psychodiagnostic testing were compared.

\section{B. Research Findings Were Described and Summarized}

Respondents were 60 St. Petersburg instructors with teaching experience of over 5 years (average teaching experience is 10.3 years). Respondents age was from 25 to 58 years. $80 \%$ of the instructors were women, $20 \%$ were men. The test group included 32 persons who completed supplementary educational program (SEP) "Higher education instructor" at St. Petersburg State University in 2010-2015, 28 persons were included in the reference group (the instructors who did not attend SEP). "Table I"

TABLE I. TEST AND REFERENCE GROUPS OF HIGHER EDUCATION INSTRUCTORS

\begin{tabular}{|c|c|c|c|c|c|c|c|}
\hline \multirow[t]{3}{*}{ No. } & \multirow[t]{3}{*}{ Position, Degree } & \multirow{2}{*}{\multicolumn{2}{|c|}{ Number of Persons in the Group }} & \multicolumn{4}{|c|}{ Gender Composition } \\
\hline & & & & \multicolumn{2}{|c|}{ Test Group } & \multicolumn{2}{|c|}{ Reference Group } \\
\hline & & test group & reference group & $m$ & $f$ & $m$ & $f$ \\
\hline 1 & Professor & 5 & 5 & 2 & 3 & 1 & 4 \\
\hline 2 & Associate Professor & 7 & 6 & 2 & 5 & 3 & 3 \\
\hline 3 & Senior instructor & 9 & 5 & 0 & 9 & 1 & 4 \\
\hline 4 & Instructor & 4 & 3 & 0 & 4 & 1 & 2 \\
\hline 5 & Assistant & 7 & 9 & 2 & 5 & 0 & 9 \\
\hline 6 & Total & 32 & 28 & 6 & 26 & 6 & 22 \\
\hline
\end{tabular}

The test and reference groups were balanced in terms of professional status, gender composition and disciplines.

It did not seem possible to make the groups "by the discipline" as the survey covered instructors in too many disciplines (journalism, applied mathematics, sociology, economics, psychology, medicine, law, physical education and sport, history, geography, geology, etc.).

\section{Methods of Psychodiagnostics}

- The study of cognitive-emotional components of the self-consciousness in the self-conception form (checklist by V.V. Stolin, S.R. Panteleyev).

- The study of cognitive components of the selfconsciousness in the form of life-purpose guides (LPG test adapted by D.A. Leontyev).

- The study of psychological defenses as mechanisms stabilizing the self-concept (checklist by KellermanPlutchik).

- The study of behavioral component of the selfconsciousness as behavioral styles in a conflict (method by K. Thomas).

- Diagnostics of the "professional burnout" symptoms (checklist by V.V. Boyko).

The empirical research covered 42 factors in total.

Statistical data processing was completed using SPSS 20 software.

\section{THEORETICAL BASIS OF EMPIRICAL RESEARCH}

Many studies by Russian (L.I. Bozhovich, D.I. Feldstein, A.A. Brudny, M.M. Bakhtin, V.V. Znakov, B.V. Kaygorodov, T.V. Stepkina et al.) and foreign (W. Damon, D. Hart, K. Blaga, M. Shebek, S. Cook-Greuter et al.) psychologists confirm the relationship between functional activity of various self-consciousness components and personal behavior, including professional self-fulfillment [8, $14,15]$.

Normally, the self-consciousness theory distinguishes the following structural or functional components: self-image, self-assessment, self-conception, self-concept, selfadjustment, etc. Psychologists determined that some of the aforementioned self-consciousness components had a particular value at certain stages of lifespan development, such as development of a correct self-assessment in teenagers [5]. Other components, to a greater degree, reflect functionality of the self-consciousness in the context of person's professional activities, for example, the professional self-concept [3]. Other categories of the self-consciousness are also distinguished that one can use for estimating the degree of personal maturity, for example, self-understanding [4]. According to B.V. Kaygorodov (2000), one of key methods for achieving higher efficiency and satisfaction with life and activities is developing the level of personal selfunderstanding [4]. Russian psychologists studied essential characteristics of self-understanding in adolescent age $[5,13]$, in high-school age [6], in professional development of students, for example, future teachers [13]. However, there are very few studies dedicated to investigating the specific 
patterns in development of self-understanding of teachers at different phases of professional self-fulfillment [2]. Probably, it can be explained by the fact that investigating the specific patterns in development of self-understanding of the teacher (especially the higher education instructor) is complicated by teachers' personal prejudice regarding the "correct" psychological psychodiagnostics. Nonetheless, psychodiagnostic testing of personal attributes and the feedback the respondent gets from the psychologist stimulate reflection and, normally, the respondent develops a need for "self-analysis". We agree with Professor N.B. Vitanova with her reasoning that "by way of stimulating self-reflection and subjective attitude to the professional self" [1; 432] one creates "internal prerequisites for the professional and personal functioning" [1;432].

\section{PRoblem, SCIENTIFIC AND PRACTICAL VALUE OF RESEARCH}

\section{A. Problem of Research}

We identified the "problem field" where the meaningful focus is investigating how the "growing self-understanding" of a higher education instructor "impacts" the changes in the content and relationships of the self-consciousness components. It is our understanding that development of self-understanding is an on-going process accompanying professional growth of a person whose content is development of the self meta-knowledge by way of accumulating generalizations in the self-images and selfevaluations that reflect the most meaningful elements of behavioral, cognitive and emotional experience of a person; self-understanding drives self-determination with regard to life goals and self-management in professional activities.

\section{B. Scientific Value of Research}

Scientific value of studying the phenomenology of different aspects of self-consciousness in higher education instructors stems from the fact that instructors create the educational environment in which students' personal and professional growth takes place. Personal growth of higher education instructor is associated with his/her selfconsciousness; instructor's personal defenses against workspecific stress factors arising from the educational environment are also supported by his/her self-consciousness [12]. The conceptual importance of empirical data related to this problem and insufficient level of knowledge stand in contradiction.

\section{Practical Value of Research}

The practical value of investigating the self-conscious components of the higher education instructor is explained by the need to identify "targets" for psychological support of the teaching staff, so obvious for education psychologists [11]. Instructors at different phases of their professional activities need particular forms of psychological "follow-up" $[9,10]$.

Thus, we identified the "problem field" where the meaningful focus is investigating how the "growing self- understanding" of a higher education instructor "impacts" the changes in the content and relationships of the selfconsciousness components. It is our understanding that development of self-understanding is an on-going process accompanying professional growth of a person whose content is development of the self meta-knowledge by way of accumulating generalizations in the self-images and selfevaluations that reflect the most meaningful elements of behavioral, cognitive and emotional experience of a person; self-understanding drives self-determination with regard to life goals and self-management in professional activities.

\section{IDEOLOGY OF EMPIRICAL RESEARCH}

The conceptual content of this study relies on fifteen years of experience in delivering the course "Higher education instructor" (at the department of psychology of St. Petersburg State University) to provide advanced psychological and pedagogical training for instructors. The "Teacher's psychology" course and personal growth exercises for instructors suggests that the reality of selfconsciousness of instructors (in disciplines other than psychology) develops in parallel with the process of building up professional competence. It was found out during an earlier study that the development of greater psychological competence in instructors was beneficial for the development of higher-level self-understanding (as one of the aspects of the self-consciousness) [9]. Such personal growth activates professional self-fulfillment and contributes to preventing and, in some instances, correcting disorders in physical and psychological health of instructors [11].

Even some high-profile instructors need psychological skills to effectively "manage" their personal qualities in professional activities, utilize personal attributes and professional experience and tap into their "reserve" of selfconsciousness in a challenging situation. Such skills, as experience of surveys and content analysis of instructors' self-reports demonstrates, help building up a psychological reserve for overcoming professional and personal difficulties.

Taking into consideration that inclusion of a new skill into person's self-consciousness occurs in a staged manner and has many aspects, we have made an attempt to identify meaningful aspects of the "self" and provided situational conditions for self-analysis. The analysis covered selfconception characteristics, behavioral styles in conflict environments, psychological dysfunction symptoms, personal life-purpose guides and psychological defense mechanisms.

\section{PROGRAM FOR DEVELOPMENT OF SELF-ANALYSIS FOR HIGHER EDUCATION INSTRUCTORS}

The self-analysis program comprised four sessions.

\section{A. Session 1}

Discussing senses and ideals the instructors aspire to implement in their professional activities, identifying professional abilities that the instructors deem necessary to be utilized in the teaching process. In parallel, a situation- 
driven assessment of personal professional achievements is carried out. A professional's self-assessment is subject to "testing" in several ways: (1) by comparing his/her performance with the competence standards common to all instructors; (2) in connection with self-survey of professional activities based on subjective professional growth benchmarks; (3) highlighting (in some cases, by "insight") his/her top-priority personal qualities (relevant for instructor's professional activities) and association with such qualities. Such self-analysis results in "understanding" the personal self concept of a professional.

This "phase" in development of the self-consciousness can be termed as "the cognitive phase". The indicators reflecting the self-consciousness dynamics are changes in the self-assessment of the "self" and professional achievements.

\section{B. Session 2 .}

Analysis of the states and feelings associated with professional activities, constituting the background of professional activities and expressing the attitude towards professional activities. Cognitive and emotional selfawareness of the "self" specific individualities is manifested in the process of experience.

\section{Session 3 .}

Self-analysis of motivations, individual life goals and self-fulfillment aspects. Significance of the professional teaching activity among other meaningful purposes (material wealth, family, children, etc.) is analyzed. This deliberations make one assess the outlooks and determine their value for the family, friends and himself/herself. Value-based perception of self and attitude of the meaningful others towards self is clarified.

\section{Session 4.}

Generalizing the experience of reflection and selfanalysis allows the aspects of the perceived "self" to be expanded to include appearance and behavior specifics, professional qualities that offer a new point of view for "assessment" of one's success in life and professional carrier; self-knowledge, associated with analyzing one's own moral and ethical qualities, is given meaning. Eventually, it results in a higher level of self-understanding.

\section{E. Evaluation of Results of Self-analysis Development Course}

Obviously, the highlighted development aspects of instructor's self-consciousness do not reflect all the facets of this on-going process; however, the self-analysis elements described above reflect the essence of the psychological exercise.

A repeated psychodiagnostic testing was carried out to complete the self-analysis process.

\section{METHODS}

- The study of cognitive-emotional components of the self-consciousness as self-conception (checklist by V.V. Stolin, S.R. Panteleyev).

- The study of cognitive components of the selfconsciousness as life-purpose guides (LPG test adapted by D.A. Leontyev).

- The study of psychological defenses as mechanisms stabilizing the self-concept (checklist by KellermanPlutchik).

- The study of behavioral component of the selfconsciousness as behavioral styles in a conflict (method by K. Thomas).

- Diagnostics of the "professional burnout" symptoms (checklist by V.V. Boyko).

The empirical research covered 42 factors in total.

Statistical data processing was completed using SPSS 20 software.

\section{RESUlTS OF PSYCHODIAGNOSTICS OF PERSONAL ATTRIBUTES OF HIGHER EDUCATION INSTRUCTORS}

\section{A. Results of Psychodiagnostics of the Self-conception Aspects}

No reliable differences in self-conception scores between the test and the reference groups were found during the first psychodiagnostic test, which is indicative that the two groups are homogeneous in composition. The scores from the scales reflecting mostly cognitive aspects (such as self-respect, selfinterest, self-guidance) were (not statistically significant) lower than the scores reflecting mostly emotional aspects of self-conception (auto-sympathy, self-acceptance, selfaccusation). This trend took place in both groups.

The final psychodiagnostic testing revealed statistically significant differences in the "self-respect" and "selfconfidence" scales $(p \leq 0.01)$ between the scores of the test and reference groups.

It was found that the degree of instructors' statistically significant self-understanding scores turned out to be lower than the high self-interest and self-acceptance scores "Fig. 1". It was an additional point for developing this aspect of selfconsciousness. 


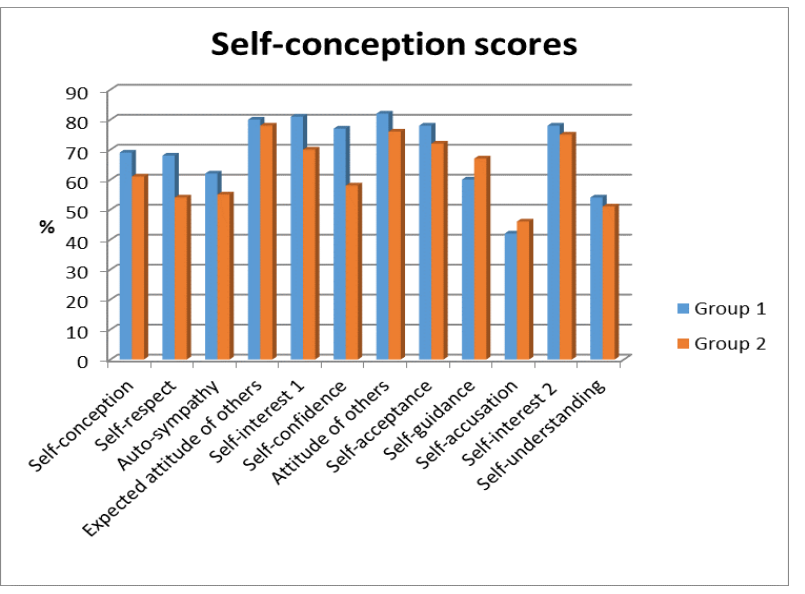

Fig. 1. Diagram of the final diagnostic self-conception scores in two groups.( 1- test group, 2 - reference group)

\section{B. Psychodiagnostic Life-Purpose Guide Scores}

The method of LPG diagnostics uses scales showing the maturity level of: (1) The purpose that determines the time perspective direction. (2) The interest reflecting the emotional saturation and meaningfulness. (3) Satisfaction from self-fulfillment reflecting the appraisal of the life journey made so far. (4) Control of the "self" showing perception of self as a personality with a sufficient freedom of choice for managing own life in line with purposes and perceptions of the life purpose. (5) Confidence that one is capable of controlling his/her life.

The first psychodiagnostic test did not reveal any significant differences between the test and reference groups. An average level of scores achieved during the test allows the respondents to be characterized as goal-oriented, confident in their ability to control own life, perceiving their lives as interesting and full of meaning, and satisfied with self-fulfillment. From the trends perspective, all scores of the first group were higher. It may be indicative that the instructors who started the "Higher education instructor" educational program had somewhat higher expectations for the productivity of life.

Based on the final psychodiagnostic scores shown by the instructors from the two compared groups, significant differences were noted for the life manageability scale: $33.41 \pm 7.91$ and $29.20 \pm 4.26(\mathrm{p} \leq 0.05)$. Confidence in life manageability grew stronger following a self-analysis exercise.

\section{Psychodiagnostic Scores in "Behavior Style", Defense Mechanisms and "Burnout" Symptoms}

As the scores from the initial and final psychodiagnostic testing were compared to look into these factors, it appeared that the test group showed more positive scoring. For instance, the "collaboration" behavior style score increased significantly $(\mathrm{p} \leq 0.01)$, while the "avoidance" style score came down $(\mathrm{p} \leq 0.001)$. The overall "activity" of defense mechanisms came down, while the "compensation" mechanism score went up significantly $(\mathrm{p} \leq 0.01)$. Average scores for the "psychological stress" syndrome complex also came down $(\mathrm{p} \leq 0.01)$.

As the scores from the second psychodiagnostic test were compared, it was found that the test group displayed positive changes for 16 factors (out of 42). Positive changes for 7 factors (out of 42) were also noted in the reference group as such changes were manifested by higher scores.

By comparing the quantity and content of the changes noted in the instructors from the test and reference groups, we can characterize the self-analysis process as having effects on various aspects of the instructors' selfconsciousness.

The following data can be considered as indicators of the "personal growth" of the instructors who took part in the self-analysis process: cognitive self-consciousness components (life management, self-respect, self-confidence) became more pronounced; defense mechanisms in emotional self-consciousness components became less expressed, also less pronounced was the "psychological stress" symptom; behavioral self-consciousness components showed a "growth" in the "collaboration" score and a reduction in the "avoidance" behavioral style.

\section{Results of Correlation Analysis}

Statistically significant relationships between the factors under investigation were identified, they are shown in "Table II".

TABLE II. RELATIONSHIPS BETWEEN SELF-CONSCIOUSNESS COMPONENTS AT P $\leq 0.001$, TEST AND REFERENCE GROUPS (1- INITIAL PSYCHODIAGNOSTIC TEST; 2- Final Psychodiagnostic Test)

\begin{tabular}{|c|c|c|c|c|c|c|c|c|}
\hline & \multicolumn{2}{|c|}{ Test Group } & \multirow{2}{*}{$\begin{array}{r}1 \\
0.47\end{array}$} & \multirow{2}{*}{$\begin{array}{r}2 \\
-\end{array}$} & \multicolumn{2}{|c|}{ Reference Group } & \multirow{2}{*}{$\frac{1}{0.52}$} & \multirow{2}{*}{$\begin{array}{c}\mathbf{2} \\
0.54\end{array}$} \\
\hline 1 & self-respect & psychological stress & & & $\begin{array}{l}\text { Integral self- } \\
\text { conception }\end{array}$ & Psychological stress & & \\
\hline 2 & auto-sympathy & LPG result control & 0.63 & 0.23 & auto-sympathy & LPG life control & 0.42 & 0.41 \\
\hline 3 & LPG process control & trade-off behavioral style & 0.41 & - & LPG process control & trade-off behavioral style & 0.62 & 0.58 \\
\hline 4 & LPG process control & behavioral style collaboration & - & 0.44 & & & & \\
\hline 5 & Avoidance style & $\begin{array}{ll}\text { Emotional detachment } \\
\text { symptom }\end{array}$ & 0.67 & - & Avoidance style & Emotional thriftiness & 0.40 & 0.49 \\
\hline 4 & $\begin{array}{l}\text { behavioral style } \\
\text { collaboration }\end{array}$ & growing psychological stress & - & -0.61 & Collaboration style & growing psychological stress & - & 0.42 \\
\hline 5 & Defense by substitution & Exhaustion symptom & 0.49 & - & $\begin{array}{l}\text { Defense } \\
\text { substitution }\end{array}$ & Exhaustion symptom & 0.59 & 0.47 \\
\hline 6 & Defense by substitution & LPG locus of result control & - & 0.61 & $\begin{array}{l}\text { Defense } \\
\text { suppression }\end{array}$ & detachment & - & 0.66 \\
\hline
\end{tabular}


The identified relationships between the instructors' selfconsciousness components reflect dynamic trends in the relation structure of the investigated factors in the test group and absence of any expressed dynamic patterns in the reference group.

Initially, relationships between the self-conception factors (self-respect and integral self-conception) and the "psychological stress" symptom were characteristic for both compared groups; however, final scores of the test group suggest that everything contributing to the emergence of selfrespect is not (explicitly) related to psychological stress, whereas this relationship persists in the reference group.

Significant relationships were identified between the "auto-sympathy" emotional self-consciousness component and the "result control" and "life control" cognitive components. This relationship emphasizes the occupational context of the instructors' auto-sympathy.

Development of self-understanding level in the test group instructors can be distinguished by transformation in the relationship of the LPG "process control" score with the "trade-off" behavioral style (initially, relationship was noted in both groups); however, following the self-analysis exercise, the LPG "process control" score turned out to have a relation with the "collaboration" style.

Further, the "avoidance" conflict behavioral style (a behavioral component of the self-consciousness) at the initial psychodiagnostic testing appeared to have a significant relationship with the "emotional detachment" and "emotional thriftiness" symptoms; after self-analysis, however, this style did not manifest amongst the relationships in the test group, but a strong negative relationship was uncovered between the collaboration behavioral style and the "psychological stress" symptomatology.

Correlation analysis of the scores from the final psychodiagnostic test suggests the instructors who attended self-analysis sessions experience growing self-understanding. For instance, a relationship was found in the initial psychodiagnostic test data between the "substitution" defense mechanism and the "exhaustion" symptom; however, the final psychodiagnostic test did not show this relationship as statistically significant, while the significant relationship turned out to be the one between the "substitution" and the "result control" cognitive self-consciousness element. These transformations can be interpreted as follows: the initial psychodiagnostic test had a pattern of factors reflecting only negative psychophysiologic reaction (syndrome complex: "substitution-exhaustion"); after the training course the resultant relationship rather acquired a content of the coping mechanism (substitution - result control). Thus, cognitive regulatory component of the self-consciousness became more "active".

\section{IX, SUMMARY}

Summary: there are grounds to believe that activating self-consciousness of the instructors by training contributed to reducing statistically significant relationships with negative content and a greater degree of cognitive regulation of conflict behavior or at dysfunctional reactions.

No similar relationship transformations were identified in the reference group.

Based on the outcome of the empirical research we have conducted, the following conclusion is drawn: "self-analysis" of different aspects of instructors' self-consciousness had a positive effect on changes in the scores of cognitive, emotional and behavioral components of the selfconsciousness; content of the relationships also undergone changes and relationships became "closer".

Theoretical novelty of the findings is comprised of revealing the interconditionality between the specific components of the self-consciousness with cognitive, emotional-behavioral, value-meaning content, as well as between these components and protective and dysfunctional manifestations of the "self".

\section{Research Perspectives}

Possible relationship between the status of higher education instructor and the level of his/her selfunderstanding was not investigated in this research. It is also possible that instructor's "successful career-making" is related to self-understanding. Presumably, these hypotheses may constitute a basis for a subsequent stage of our research on self-consciousness of higher education instructors.

\section{CONCLUSION}

Summarizing the collected empirical data, we can draw the following conclusions:

- The characteristic under investigation was the selfconsciousness. We examined the self-consciousness as an integral formation that incorporated cognitive, emotional, behavioral components of the "self", more specifically: self-conception, perception of the own life-purpose guides, behavioral styles, as well as perceptions of defense mechanisms and potential manifestations of professional "burnout".

- It has been established that regardless of professional status and work experience, instructors demonstrate "personal growth" when their self-understanding is activated by the method of self-analysis.

- The level and content of transformations in the relationships of the investigated factors suggest that self-consciousness activated by particular psychological methods can determine personal growth in instructors of higher educational institutions.

\section{REFERENCES}

[1] Vitanova N.B. Opportunities for developing attitude to the professional self in students // Collection of scientific reports at the $7^{\text {th }}$ national psychology congress. Sofia, 31. X.-2. XI. 2014. Sofia, 2014. pp. $432-440$. 
[2] Dakhina T.V. Psychology of developing self-understanding in higher education instructors at the period of adapting to professional activity. Abstract of Sc. Cand. (Education) thesis, 19.00.13, Astrakhan, 2007.

[3] Dzhaneryan S.T. Professional self-concept. Systematic approach. Abstract of doctoral thesis in psychology, Rostov-on-Don, 2005.

[4] Kaygorodov B.V. Self-understanding: myth or reality. Moscow: Moscow Institute for Psychology and Social Studies, 2000

[5] Kon I.S. Looking for self: personality and sub-consciousness. Moscow, 1984.

[6] Monakhova I.A. Psychological aspects of self-understanding in highschool age. Abstract for Sc. Cand. (psychology) thesis, 19.00.07., Astrakhan, 2002.

[7] Petanova E.I. Relation of cognitive and emotional components of self-consciousness in behavior control of higher education instructors // Relevant socio-psychological problems of personality development in $21^{\text {st }}$ century educational environment. Kazan, 2008. - p. 249.

[8] Petanova E.I., Rean A.A. General psychology and psychology of personality. // edited by A.A. Rean, St. Petersburg: PrimeEVROZNAK, 2009. $-639 \mathrm{p}$.

[9] Petanova E. I. Specifics of self-consciousness of higher education instructors. Bulletin of St. Petersburg State University, Series 12, Issue 4, 2010. pp. 99-105.

[10] Petanova E.I. Development of self-understanding in higher education instructor at early professional evolution. Psychology of instructor (Textbook). St. Petersburg: Publishing house of St. Petersburg State University. 2013. pp. 27-33.

[11] Petanova E. I. "Character accentuation" as a factor of risk of developing "emotional burnout" symptoms in future higher education instructors. // Professional and personal development of future specialist: a collection of papers / edited by RAS Academician N.V. Bordovskaya. - St. Petersburd: Publishing house of St. Petersburg State University., 2012. - pp.184-196.

[12] Petanova E. I. Health of higher education instructors (Textbook). St. Petersburg: Publishing house of St. Petersburg State University, 2014.

[13] Protasova N.I. Development of self-understanding in young men and women in the process of professional training of future teachers. Abstract for Sc. Cand. (psychology) thesis. Moscow, 1999.

[14] Romanova I.A. Main lines of research of self-understanding in foreign psychology // Journal of psychology. 2001. Vol. 22, No. 1.pp. $102-112$

[15] Stepkina T.V. Psychological fundamentals of studying selfunderstanding in Russian and foreign science. // Bulletin of N.A. Nekrasov Kostroma State University. Science and methodology journal. Acmeology of education series. 2007. Vol.13. pp.196-200. 